\title{
The Role of Visfatin in Diabetic Nephropathy
}

\author{
Young Sun Kang* and Dae Ryong Cha \\ Department of Nephrology, Korea University Medical College, Ansan, Korea
}

As a result of the energy overload in obesity, insulin resistance, type 2 diabetes, dyslipidemia, hypertension, and atherosclerosis develop, which together comprise the metabolic syndrome. Although the kidney becomes a victim of hyperglycemia in diabetes mellitus, recent work has shown that the abnormalities of lipid and glucose metabolism in the kidney are similarly important to those in adipose tissue. Interestingly, obesity triggers the release of adipokines such as leptin, resistin, and visfatin, and these can then be associated with the progression of diabetic nephropathy and other vascular complications. These adipokines, which are also synthesized in the kidney, appear to have an important role in renal injury associated with insulin resistance. Our studies found that visfatin is not only a surrogate marker of systemic inflammation in type 2 diabetic patients but is also up-regulated in diabetic kidney through the uptake of glucose into renal cells, which leads to the activation of the intracellular insulin signaling pathway and pro-inflammatory mechanisms. However, we also observed a beneficial effect of visfatin administration to type 2 diabetic mice. Visfatin injection improved diabetic nephropathy in vivo, in contrast to our previous in vitro study of cultured renal mesangial cells. These results suggest the possibility of multiple cross-talk between adipose tissue and kidney in the metabolic syndrome, particularly in diabetic nephropathy. Further study should be undertaken to understand the role of adipose tissue and kidney as major organs in the metabolic syndrome.

\section{Key Words: Nicotinamide phosphoribosyltransferase; Diabetic nephropathy}

This is an Open Access article distributed under the terms of the Creative Commons Attribution Non-Commercial License (http://creativecommons.org/licenses/by-nc/3.0) which permits unrestricted non-commercial use, distribution, and reproduction in any medium, provided the original work is properly cited.

\section{Article History:}

received 24 November, 2011 accepted 29 November, 2011

\section{Corresponding Author:}

Young Sun Kang

Department of Nephrology, Korea University Medical College, Ansan Hospital, 516 Gojan-dong, Ansan 425-020, Korea

TEL: +82-31-412-6739

FAX: $+82-31-412-5574$

E-mail: starch70@korea.ac.kr

\section{INTRODUCTION}

The kidney is a major target organ in the metabolic syndrome, such as in diabetes mellitus. Although the kidney becomes a victim of hyperglycemia, its central role in glucose metabolism and insulin resistance has not been identified. However, it was recently considered that the kidney plays an important role in glucose metabolism, and there are frequently abnormalities in glucose metabolism in patients with chronic kidney disease. ${ }^{1}$ There is also considerable evidence from animal studies for renal glucose production and utilization. ${ }^{2-4}$ The roles of the kidney in glucose metabolism and energy homeostasis have recently been discussed under the development of new antidiabetic drugs. 5,6

Recent studies have shown that adipose tissue is a highly metabolic organ with pleuripotent functions far beyond the mere storage of energy. Adipose tissue is now known to be an endocrine organ that secretes a large number of bioactive proteins, called adipokines, that have essential roles in energy homeostasis, glucose and lipid metabolism, insulin resistance, inflammation, and atherosclerosis. ${ }^{7,8}$ These include several active molecules released by adipocytes, such as leptin, resistin, and adiponectin, as well as cytokines released by inflammatory cells, such as tumor necrosis factor (TNF)- $\alpha$, interleukin (IL)-6, macrophage/ monocyte chemoattractant protein (MCP)-1, and interleukin (IL)-1. Interestingly, the circulating levels of these adipokines have been found to be altered in experimental animals and patients with chronic kidney disease, which is an independent risk factor of cardiovascular mortality. Furthermore, their production, secretion, and regulatory actions are not limited to adipose tissue, but are described in other organ tissues as well. For example, it is now recognized that the kidney itself can alter the clearance of adipokines and produce them.

Among these adipokines, visfatin is a ubiquitous intra- 
cellular enzyme, also called nicotinamide phosphoribosyltransferase (NAMPT)/pre-B cell colony-enhancing factor (PBEF)-1. It was originally characterized from lymphocytes, and its enzymatic biochemical basis and structure have been established. ${ }^{9-11}$ NAMPT constitutes a nuclear nicotinamide adenine dinucleotide $\left(\mathrm{NAD}^{+}\right)$salvage/recycling pathway, which regulates the functions of $\mathrm{NAD}^{+}$-dependent enzymes, such as the protein deacetylase sirtulin (SIRT)1. ${ }^{12}$ NAMPT, a unique rate-limiting enzyme encoded by a single gene, catalyzes the conversion of nicotinamide (NAM) to nicotinamide mononucleotide (NMN), which in turn is converted into $\mathrm{NAD}^{+}$by nicotinamide mononucleotide adenylyltransferase (NMNAT)-1. NAD ${ }^{+}$is an important signaling molecule and a coenzyme in metabolic processes and redox reactions; it is consumed as a donor of $\mathrm{ADP}$-ribose with the release of NAM as a byproduct. NAMPT has been proved as a critical NAD biosynthetic enzyme that regulates the activity of SIRT-1 in mammalian cells. ${ }^{11}$ Finally, SIRT-1 and NAMPT-mediated systemic $\mathrm{NAD}^{+}$biosynthesis together play an important regulatory role in glucose homeostasis, particularly in the glucose-stimulated insulin secretion of pancrease in the pathophysiology of type 2 diabetes. ${ }^{13}$ The insulin-mimetic effect of NAMPT, referred to as visfatin, has recently been studied in obesity and type 2 diabetes mellitus. In this review, the role of visfatin in diabetic nephropathy will be summarized and discussed.

\section{VISFATIN IN DIABETIC NEPHROPATHY}

\section{The role of visfatin as an adipokine}

Visfatin is increased in inflammatory conditions such as acute lung injury, sepsis, and rheumatoid arthritis. ${ }^{14-16}$ Thus, it is considered to be a proinflammatory adipokine via either a compensatory response or an epiphenomenon. Of note, visfatin was recently reported to be expressed almost exclusively in visceral adipose tissue rather than subcutaneous adipose tissue. Adipokines, which are secreted by adipocyte tissue, have been studied in association with insulin resistance and the metabolic syndrome, including obesity, glucose intolerance, and dyslipidemia.

However, studies of visfatin in human populations have obtained conflicting results. Elevated plasma visfatin levels have been reported in patients with type 2 diabetes mellitus. ${ }^{17-20}$ On the other hand, other investigative results showed decreased plasma visfatin levels in patients with type 1 diabetes, liver cirrhosis, exercise in type 2 diabetes, and 3rd trimester gestational diabetes. ${ }^{21-25}$ Elevated visfatin levels were also shown in hemodialysis patient $\mathrm{s}^{26,27}$ and a positive correlation of visfatin levels with all stages of chronic kidney disease was observed. ${ }^{28}$ Yilmaz et al. ${ }^{29}$ published that visfatin levels were positively associated not only with insulin resistance but also with the degree of albuminuria in type 2 diabetic patients. They suggested that the endothelial dysfunction in early diabetic nephropathy is associated with altered circulating levels of visfatin. However, in another experimental study, visfatin was shown to activate endothelial nitric oxide synthase (eNOS) via Akt and mi- togen-activated protein (MAP) kinase and MCP-1 and improve endothelial cell function, angiogenesis, and atherosclerosis. ${ }^{30,31}$ Thus, controversy exists among clinical studies and experimental data for the role of visfatin in diabetic nephropathy. Whether this phenomenon primarily arises from direct vascular defects or is secondary to the presence of visceral obesity and a deranged metabolic milieu that is characteristic of many patients with diabetes remains unclear.

Consistent with several reports, we observed that plasma visfatin levels were elevated in patients and animals with type 2 diabetic nephropathy. ${ }^{32,33}$ Interestingly, in our in vitro study, ${ }^{34}$ visfatin was synthesized in renal glomerular mesangial cells, upregulated by high glucose stimulation. In addition, exogenous visfatin stimulation in renal cells upregulated the synthesis of profibrotic molecules, including transforming growth factor (TGF)- $\beta 1$, plasminogen activator inhibitor (PAI)-1, and type I collagen. Given these findings, the pathophysiologic relevance of visfatin seems to be as a proinflammatory adipokine regarding type 2 diabetes and other metabolic complications.

\section{The insulin-mimic effect of visfatin}

Despite the insulin-mimic effect of visfatin, controversy exists over its role insulin resistance. The exciting paper of Fukuhara et al., which had described the insulin-mimetic effect of visfatin and its naming, has been finally retracted. Several studies failed to show an association of circulating visfatin with insulin sensitivity. ${ }^{19,35-37}$ There has been no report of whether the relation between visfatin and insulin is synergistic. However, it is still interesting whether visfatin binds directly to the insulin receptor at a site distinct from insulin and has hypoglycemic effects by reducing glucose release from hepatocytes and stimulating glucose utilization in peripheral tissue. ${ }^{38}$ Insulin receptor expression has been ascertained in renal cells such as proximal tubular cells, mesangial cells, and podocytes. However, the affinity of visfatin for the insulin receptor and other receptors such as insulin-like growth factor receptor and insulinreceptor like receptor is unclear. In fact, insulin also binds with low affinity to insulin-like growth factor receptor and insulin-receptor like receptor in kidney. A recent study reported that insulin receptor expression was shown to be reduced in the kidney of an insulin-resistant rat animal model. ${ }^{39}$ Despite a high plasma insulin level, decreased insulin receptor expression has been explained to correlate with insulin resistance in various tissues such as liver, skeletal muscle, and adipose tissue. However, this finding in the kidney can be different among renal cells and may be distinct depending on the organ type, i.e., whether liver, skeletal muscle, or adipose tissue. On the other hand, another study suggested that visfatin does not have insulinmimetic actions but rather has a regulatory role in glucosestimulated insulin secretion in pancreatic $\beta$-cells in vitro and in vivo. ${ }^{40}$ Those authors demonstrated that mice lacking visfatin synthesis develop impaired glucose tolerance and defective insulin secretion, which are restored by admin- 
istration of visfatin. Taken together, these results suggest that visfatin may act as a multiplayer in either a cell- or tissue-dependent manner.

Interestingly, in our in vitro study, ${ }^{34}$ high glucose stimulation upregulated visfatin synthesis and then visfatin stimulated glucose uptake via the glucose transporter (GLUT)-1 in renal mesangial cells. However, angiotensin ll stimulation did not induce visfatin synthesis. We found that exogenous visfatin stimulation in renal mesangial cells upregulated the insulin signaling pathway and induced synthesis of its downstream components of profibrotic molecules.

In contrast, another study published data indicating that life span extension in mice is associated with reduced insulin receptor signaling cascade, which upregulates the expression of SIRT-1 proteins. ${ }^{41}$ Therefore, there could be possible cross-talk between the visfatin-mediated and insulin signaling pathways via various physiologic mechanisms. $^{42}$

\section{Visfatin as a nicotinamide adenine dinucleotide (NAD) biosynthetic enzyme}

Recent studies have shown that disturbances in the circadian clock feedback cycle through NAMPT/visfatin-mediated $\mathrm{NAD}^{+}$biosynthesis may cause an imbalance in energy metabolism and homeostasis. ${ }^{13}$ Other data showed that this optimizing of SIRT1-mediated p53 degradation by visfatin induces the extension of human cell life span, such as smooth muscle cells, and the resistance to oxidative stress. ${ }^{43}$ If visfatin is impaired in the aging-dependent circadian cycle and this leads to the decline of pancreatic cell function in type 2 diabetes, visfatin could be an effective target for the treatment and prevention of type 2 diabetes.

Furthermore, a recent study suggested that angiotensin ll plays a role in the prolongation of the life span in mice. ${ }^{44}$ Agtr1a-/- mice developed a longevity phenotype and upregulation of visfatin expression in the kidney. Although high glucose stimulation induces renal cell visfatin synthesis and intracellular glucose transport, which leads to increased pro-fibrotic molecular expression as demonstrated in our previous in vitro study, ${ }^{34}$ angiotensin 11 did not induce visfatin synthesis and mice lacking angiotensin receptor expressed visfatin upregulation. Taken together, these data suggest that visfatin may have multiple actions in the kidney, even in the regulation of NAD-consuming enzymes such as sirtuins. In fact, we examined the effect of intraperitoneal visfatin administration on diabetic nephropathy in mice. In our in vivo study, visfatin had a protective effect on the albuminuria of diabetic nephropathy in mice (data not published). Exogenous visfatin infusion did not show a large glucose-lowering effect through glucose uptake into renal cells. Besides, the plasma visfatin concentration is much lower than the insulin concentration, although the affinity of visfatin for the insulin receptor appears to be similar to that of insulin. ${ }^{45}$ Although high glucose stimulates intrarenal cellular visfatin synthesis, and then glucose taken up by renal cells activates the intracellular signaling pathway leading to injury in diabetic nephropathy, plasma visfatin elevated by autocrine action may act via a different regulatory pathway. The enzymatic and functional role of visfatin remains unknown in the kidney. ${ }^{42}$ Therefore, visfatin has a compensatory effect via both autocrine and paracrine pathways to improve insulin resistance and lipid metabolism. Particularly, one study showed that long-term visfatin infusion does not decrease the abundance of insulin receptors in the kidney of insulin-resistant rats, which is different in other tissues, such as liver, skeletal muscle, and adipose tissue. ${ }^{39}$ It is also possible that a more physiologic route of intraperitoneal visfatin injection may have benefit compared with vascular infusion, which is directly accumulated in the liver and visceral adipose tissue, which are the main organs regulating lipid and glucose metabolism, before sufficient concentration levels are reached in the systemic circulation of plasma, heart, and kidney. In addition, an unknown receptor for visfatin may exist, which could indirectly affect the insulin signaling pathway. For example, the enzymatic regulatory action of NAMPT/ visfatin-mediated NAD synthesis might have a major effect on diabetic nephropathy through a different pathway. Nonetheless, it is equally possible that differences in the models of insulin resistance studied may have accounted for this seeming discrepancy.

\section{CONCLUSION}

Controversy remains concerning the pleiotropic roles of visfatin, although its enzymatic regulatory functions have already been identified with energy metabolism. The interesting point is that visfatin appears to act as a multiplayer adipokine in inflammation, obesity, the metabolic syndrome, and cardiovascular disease, including diabetic nephropathy. Particularly in humans and animals with type 2 diabetic nephropathy, the results of several studies suggest that visfatin could be a surrogate marker. On the other hand, its direct administration might be beneficial or harmful depending on species, organs, and cell types. There is no doubt about its different effects on various diseases. Therefore, further studies need to be performed to clarify the effects of visfatin on cellular metabolism and physiology, ultimately leading to adjustments of therapeutic strategies for metabolic and other diseases in humans.

\section{DISCLOSURES}

None.

\section{ACKNOWLEDGEMENTS}

This work was supported by Korea University Grant.

\section{REFERENCES}

1. Rubenstein AH, Mako ME, Horwitz DL. Insulin and the kidney. Nephron 1975;15:306-26.

2. Stumvoll M, Meyer C, Mitrakou A, Nadkarni V, Gerich JE. Renal 
glucose production and utilization: new aspects in humans. Diabetologia 1997;40:749-57.

3. Drury DR, Wick AN, Mackay EM, Hilltard N, Fitch R, Blackwell $\mathrm{ME}$, et al. Formation of glucose by the kidney. Am J Physiol 1950;163:655-61.

4. Schoolwerth AC, Smith BC, Culpepper RM. Renal gluconeogenesis. Miner Electrolyte Metab 1988;14:347-61.

5. Bailey CJ, Gross JL, Pieters A, Bastien A, List JF. Effect of dapagliflozin in patients with type 2 diabetes who have inadequate glycaemic control with metformin: a randomised, double-blind, placebo-controlled trial. Lancet 2010;375:2223-33.

6. Ishibashi Y, Nishino Y, Matsui T, Takeuchi M, Yamagishi S. Glucagon-like peptide-1 suppresses advanced glycation end product-induced monocyte chemoattractant protein-1 expression in mesangial cells by reducing advanced glycation end product receptor level. Metabolism 2011;60:1271-7.

7. Guzik TJ, Mangalat D, Korbut R. Adipocytokines - novel link between inflammation and vascular function? J Physiol Pharmacol 2006;57:505-28.

8. Lago F, Dieguez C, Gómez-Reino J, Gualillo O. Adipokines as emerging mediators of immune response and inflammation. Nat Clin Pract Rheumatol 2007;3:716-24.

9. Samal B, Sun Y, Stearns G, Xie C, Suggs S, McNiece I. Cloning and characterization of the cDNA encoding a novel human pre-B-cell colony-enhancing factor. Mol Cell Biol 1994;14:1431-7.

10. Martin PR, Shea RJ, Mulks MH. Identification of a plasmid-encoded gene from Haemophilus ducreyi which confers NAD independence. J Bacteriol 2001;183:1168-74.

11. Revollo JR, Grimm AA, Imai S. The NAD biosynthesis pathway mediated by nicotinamide phosphoribosyltransferase regulates Sir2 activity in mammalian cells. J Biol Chem 2004;279:5075463.

12. Zhang T, Berrocal JG, Frizzell KM, Gamble MJ, DuMond ME, Krishnakumar R, et al. Enzymes in the NAD+ salvage pathway regulate SIRT1 activity at target gene promoters. J Biol Chem 2009;284:20408-17.

13. Ramsey KM, Yoshino J, Brace CS, Abrassart D, Kobayashi Y, Marcheva B, et al. Circadian clock feedback cycle through NAMPTmediated NAD+ biosynthesis. Science 2009;324:651-4.

14. Garcia JG, Moreno Vinasco L. Genomic insights into acute inflammatory lung injury. Am J Physiol Lung Cell Mol Physiol 2006; 291:L1113-7.

15. Jia SH, Li Y, Parodo J, Kapus A, Fan L, Rotstein OD, et al. Pre-B cell colony-enhancing factor inhibits neutrophil apoptosis in experimental inflammation and clinical sepsis. J Clin Invest 2004; 113:1318-27.

16. Brentano F, Schorr O, Ospelt C, Stanczyk J, Gay RE, Gay S, et al. Pre-B cell colony-enhancing factor/visfatin, a new marker of inflammation in rheumatoid arthritis with proinflammatory and matrix-degrading activities. Arthritis Rheum 2007;56:2829-39.

17. Szamatowicz J, Kuźmicki M, Telejko B, Zonenberg A, Nikołajuk A, Kretowski A, et al. Serum visfatin concentration is elevated in pregnant women irrespectively of the presence of gestational diabetes. Ginekol Pol 2009;80:14-8.

18. Lewandowski KC, Stojanovic N, Press M, Tuck SM, Szosland K, Bienkiewicz M, et al. Elevated serum levels of visfatin in gestational diabetes: a comparative study across various degrees of glu- cose tolerance. Diabetologia 2007;50:1033-7.

19. Chen MP, Chung FM, Chang DM, Tsai JC, Huang HF, Shin SJ, et al. Elevated plasma level of visfatin/pre-B cell colony-enhancing factor in patients with type 2 diabetes mellitus. J Clin Endocrinol Metab 2006;91:295-9.

20. López-Bermejo A, Chico-Julià B, Fernàndez-Balsells M, Recasens M, Esteve E, Casamitjana R, et al. Serum visfatin increases with progressive beta-cell deterioration. Diabetes 2006;55:2871-5.

21. Toruner F, Altinova AE, Bukan N, Arslan E, Akbay E, Ersoy R, et al. Plasma visfatin concentrations in subjects with type 1 diabetes mellitus. Horm Res 2009;72:33-7.

22. Akturk M, Altinova AE, Mert I, Buyukkagnici U, Sargin A, Arslan $\mathrm{M}$, et al. Visfatin concentration is decreased in women with gestational diabetes mellitus in the third trimester. J Endocrinol Invest 2008;31:610-3.

23. de Boer JF, Bahr MJ, Böker KH, Manns MP, Tietge UJ. Plasma levels of PBEF/Nampt/visfatin are decreased in patients with liver cirrhosis. Am J Physiol Gastrointest Liver Physiol 2009;296: G196-201.

24. Brema I, Hatunic M, Finucane F, Burns N, Nolan JJ, Haider D, et al. Plasma visfatin is reduced after aerobic exercise in early onset type 2 diabetes mellitus. Diabetes Obes Metab 2008;10:600-2.

25. Chan TF, Chen YL, Lee CH, Chou FH, Wu LC, Jong SB, et al. Decreased plasma visfatin concentrations in women with gestational diabetes mellitus. J Soc Gynecol Investig 2006;13:364-7.

26. Kato A, Odamaki M, Ishida J, Hishida A. Relationship between serum pre-B cell colony-enhancing factor/visfatin and atherosclerotic parameters in chronic hemodialysis patients. Am J Nephrol 2009;29:31-5.

27. Nüsken KD, Petrasch M, Rauh M, Stöhr W, Nüsken E, Schneider $\mathrm{H}$, et al. Active visfatin is elevated in serum of maintenance haemodialysis patients and correlates inversely with circulating HDL cholesterol. Nephrol Dial Transplant 2009;24:2832-8.

28. Yilmaz MI, Saglam M, Carrero JJ, Qureshi AR, Caglar K, Eyileten $\mathrm{T}$, et al. Serum visfatin concentration and endothelial dysfunction in chronic kidney disease. Nephrol Dial Transplant 2008;23:95965.

29. Yilmaz MI, Saglam M, Qureshi AR, Carrero JJ, Caglar K, Eyileten T, et al. Endothelial dysfunction in type-2 diabetics with early diabetic nephropathy is associated with low circulating adiponectin. Nephrol Dial Transplant 2008;23:1621-7.

30. Lovren F, Pan Y, Shukla PC, Quan A, Teoh H, Szmitko PE, et al. Visfatin activates eNOS via Akt and MAP kinases and improves endothelial cell function and angiogenesis in vitro and in vivo: translational implications for atherosclerosis. Am J Physiol Endocrinol Metab 2009;296:E1440-9.

31. Adya R, Tan BK, Chen J, Randeva HS. Pre-B cell colony enhancing factor (PBEF)/visfatin induces secretion of MCP-1 in human endothelial cells: role in visfatin-induced angiogenesis. Atherosclerosis 2009;205:113-9.

32. Kang YS, Song HK, Lee MH, Ko GJ, Han JY, Han SY, et al. Visfatin is upregulated in type-2 diabetic rats and targets renal cells. Kidney Int 2010;78:170-81.

33. Kang YS, Song HK, Lee MH, Ko GJ, Cha DR. Plasma concentration of visfatin is a new surrogate marker of systemic inflammation in type 2 diabetic patients. Diabetes Res Clin Pract 2010;89:141-9. 
34. Song HK, Lee MH, Kim BK, Park YG, Ko GJ, Kang YS, et al. Visfatin: a new player in mesangial cell physiology and diabetic nephropathy. Am J Physiol Renal Physiol 2008;295:F1485-94.

35. Berndt J, Klöting N, Kralisch S, Kovacs P, Fasshauer M, Schön MR, et al. Plasma visfatin concentrations and fat depot-specific mRNA expression in humans. Diabetes 2005;54:2911-6.

36. Hammarstedt A, Pihlajamäki J, Rotter Sopasakis V, Gogg S, Jansson PA, Laakso M, et al. Visfatin is an adipokine, but it is not regulated by thiazolidinediones. J Clin Endocrinol Metab 2006; 91:1181-4.

37. Arner P. Visfatin--a true or false trail to type 2 diabetes mellitus. J Clin Endocrinol Metab 2006;91:28-30.

38. Bełtowski J. Apelin and visfatin: unique "beneficial" adipokines upregulated in obesity? Med Sci Monit 2006;12:RA112-9.

39. Tiwari S, Halagappa VK, Riazi S, Hu X, Ecelbarger CA. Reduced expression of insulin receptors in the kidneys of insulin-resistant rats. J Am Soc Nephrol 2007;18:2661-71.

40. Revollo JR, Körner A, Mills KF, Satoh A, Wang T, Garten A, et al. Nampt/PBEF/Visfatin regulates insulin secretion in beta cells as a systemic NAD biosynthetic enzyme. Cell Metab 2007;6:36375.

41. Christensen K, Johnson TE, Vaupel JW. The quest for genetic determinants of human longevity: challenges and insights. Nat Rev Genet 2006;7:436-48.

42. Garten A, Petzold S, Schuster S, Körner A, Kratzsch J, Kiess W. Nampt and its potential role in inflammation and type 2 diabetes. Handb Exp Pharmacol 2011;(203):147-64.

43. van der Veer E, Ho C, O'Neil C, Barbosa N, Scott R, Cregan SP, et al. Extension of human cell lifespan by nicotinamide phosphoribosyltransferase. J Biol Chem 2007;282:10841-5.

44. Benigni A, Corna D, Zoja C, Sonzogni A, Latini R, Salio M, et al. Disruption of the Ang II type 1 receptor promotes longevity in mice. J Clin Invest 2009;119:524-30.

45. Teoh H, Lovren F, Verma S. Vascular dysfunction: a Janus face of visfatin in diabetes? Metabolism 2007;56:459-61. 